\title{
Issue yield and party strategy in multi-party competition
}

\begin{abstract}
The issue yield model introduced a theory of the herestethic use of policy issues as strategic resources in multidimensional party competition. We extend the model by systematically addressing the specificities of issue yield dynamics in multi-party systems, with special regard to parties' issue yield rankings (relative position) and issue yield heterogeneity (differentiation) on each issue. Secondly, we introduce a novel research design for original data collection that allows for a more systematic testing of the model, by featuring: a) a large number of policy issues; b) the use of Twitter content for coding parties' issue emphasis; c) an appropriate time sequence for measuring issue yield configurations and issue emphasis. We finally present findings from a pilot implementation of such design, performed at the occasion of the 2014 European Parliament election in Italy. Findings confirm the soundness of the design and provide support for the newly introduced hypotheses about multi-party competition.
\end{abstract}

\section{Introduction}

According to a growing body of literature, the dynamics and strategies of party competition have seen a gradual but steady change in recent decades. A number of studies have shown the increasing importance of the political issues of the day for voting behaviour, on both sides of the Atlantic (Page \& Brody, 1972; Pomper, 1972; Miller, Miller, Raine, \& Brown, 1976; Nie, Verba, \& Petrocik, 1976; Carmines \& Stimson, 1980; Franklin, 1985; Franklin, Mackie, \& Valen, 1992; Alvarez \& Nagler, 1995, 1998; Borre, 2001; Heath, Jowell, \& Curtice, 2001; 
Aardal \& van Wijnen, 2005). At the same time, recent studies have clearly documented how parties have reacted to such changes, with their platforms dedicating more space to a wider variety of issues unrelated to traditional dimensions of party competition (Green-Pedersen, 2007). These dynamics appear relevant, as recent elections have shown increasing success of new, non-mainstream parties often focusing on a narrow range of issues (Hobolt \& De Vries, 2015).

What has been missing so far, however, is a general, comprehensive theoretical model of the issue selection process, i.e. of what issues should be emphasized by a party in a campaign. Previous studies have shown that parties are in part responsive to a general party system agenda (McCombs \& Shaw, 1972; Nannestad \& Paldam, 1997; Steenbergen \& Scott, 2004; Wagner, 2012), and in part focusing on issues they are known to own (Petrocik, 1996). However, no perspective to our knowledge has systematically and empirically investigated the underlying (and perhaps causally antecedent) process through which parties strategically select issues to be emphasized, e.g. according to herestethics concerns such as those theorized by William Riker (1986).

Recently, a solution to fill this gap has been introduced through the issue yield model (De Sio \& Weber, 2014). This model posits that parties select campaign issues based on two strategic considerations: a) whether a policy position on the issue is positively associated with the party (in both substantive and statistical sense); b) whether such position is also widely shared in the general electorate. If both conditions are met, that issue will allow the party to reach out to a larger voter base. The model then develops an empirical strategy, by computing - from simple survey questions - an issue yield index expressing the electoral potential offered by each issue to each party. The main testable implication of the model is that parties will give more emphasis to those issues that present a higher yield. 
The model has been mostly tested so far on comparative data on EU party systems, by relying on Manifesto data for issue emphasis and European Election Studies data for public opinion (De Sio \& Weber, 2014; De Sio, Franklin, \& Weber, 2016). Thus, all such applications are secondary analyses, relying on data collection processes that were not designed with such theory in mind. This choice is not optimal, in terms of: a) the usually small number of issues covered; b) the adequacy of Manifesto data for testing the model's hypotheses; c) the appropriateness of the time sequence in the collection of data for constructing the independent and dependent variables. Moreover, the above applications have considered the specific dynamics of multi-party competition only to a limited extent.

In this paper we present - and apply empirically - a theoretical development of issue yield theory towards multi-party competition, along with a novel research design aimed at addressing the aforementioned concerns, thus allowing more rigorous empirical testing. Such design is based on the following components: (a) a pre-electoral selection of a large number of potentially relevant issues; (b) a voter survey, whose questionnaire includes items for all the aforementioned issues, aimed at capturing issue yield configurations for each party before the campaign; (c) the collection and coding of Twitter content for each party during the campaign (according to a coding scheme covering exactly the same issues identified in step (a)), in order to properly capture the strategic campaign choices by political parties. As a pilot study, we fielded such design at the occasion of the campaign for the European Parliament elections of 2014 in Italy.

The paper is structured as follows. After this introductory section, the second section recapitulates the issue yield model and presents a new theoretical development dedicated to multi-party competition, while the third section discusses specific aspects concerning the use of Twitter data. A fourth section presents the empirical strategy and the methodological choices 
employed in the paper. The fifth section is finally dedicated to the presentation of empirical findings, followed by a concluding section.

\section{Party strategy and issue yield: a perspective for multi-party}

\section{systems}

The dynamics that govern the selection by political parties of those issues that make up their agendas and campaigns lie at the core of the process of representation, and they present a direct relationship to party competition. This is already visible in early models of party competition (Downs 1957) where the fundamental interaction between parties and voters that governs electoral competition takes place through a shared language (cf. Fuchs \& Klingemann, 1989) structured around policy issues. It is on such issues that voters assess party platforms, and it is on such issues that parties adapt themselves to fit voters' preference distributions. According to Downs, such issue language is simplified in terms of a single dimension of conflict, which under additional assumptions - allows the emergence of a Nash equilibrium, implicitly pushing parties towards the position of the median voter under certain political circumstances. The strategic virtue of such median position is that it effectively accommodates two goals of parties: expanding their voter base, while retaining as possible their extant support.

However, such conception has been also challenged, with the notable example of the valence politics framework (Stokes 1963) where the same goal - expanding the electoral base while not jeopardizing extant support - is reached through very different means. Instead of focusing on divisive issues (issues where a distribution of voter preferences exists, and where parties employ a positional strategy), a party can selectively focus on few widely shared, non-divisive goals (historical examples are related to national security, corruption and economic prosperity), where it can claim superior competence and credibility. 
The two models differ in a variety of aspects. However, from our point of view there is one aspect (overlooked by most literature) that is mostly distinctive between the two approaches, and which highlights the importance of political agendas. It is clear in Stokes' contribution that the issue agenda is not considered fixed, and is instead considered as a strategic resource, which parties have an interest in dynamically manipulating to their convenience. ${ }^{1}$

Such intuition was not followed by a systematic theoretical development before the introduction of the idea of herestethics by Riker (1986). According to Riker's intuition, parties in an unfavourable position on the main dimension of conflict (often, the left-right dimension) will concentrate their emphasis and attempt to turn the campaign debate on other issues where they enjoy a more favourable position.

The introduction of this approach raises then a key question: what are such "most favourable issues" for each party? Can a general model be proposed, capturing the incentives and disincentives that each issue offers to each party $?^{2}$ This question has received uneven attention from the literature, so that we might say that no theoretical framework (with a convincing empirical operationalization) has so far filled this gap. Obvious seminal contributions in this direction can be identified in saliency theory (Budge \& Farlie, 1983) and issue ownership (Petrocik, 1996). However, the former saw the selective issue emphasis adopted by political parties mostly as a communication tool for presenting the relatively static ideological stances of the party (Budge, 2015); and the latter, too, assumed relatively static, long-standing reputations of competence on specific issues. As a result, both approaches are not compatible with the aforementioned dynamic, strategic view of party agendas; a view which appears more and more appropriate, especially with the increasing volatility and tensions characterizing multi-party systems in Western Europe (Chiaramonte \& Emanuele, 2015; Hernández \& Kriesi, 2016). ${ }^{3}$ Recently, a more dynamic view of the strategic use of issue emphasis has been introduced with the notion of issue entrepreneurship (Hobolt \& De Vries, 2015); however, this 
concept is circumscribed by its proponents ${ }^{4}$ to what other authors have identified as niche parties (Meguid, 2008), and cannot be easily generalized to all (including mainstream) parties (Hobolt \& De Vries, 2015, pp. 1162-1165).

Following a somehow different path (relying on a dynamic, survey-based measurement of different distributions of preferences), the issue yield model has proposed a generalized model explicitly aimed at positional issues, which directly confronts the question of assessing the riskopportunity configuration offered by each issue to each party, without being limited to new issues or specific types of parties. Let us see this contribution in more detail.

\section{Issue yield}

The recently introduced issue yield model (De Sio and Weber 2014) has been presented as a model of strategic issue selection by political parties. The model addresses this question in two steps: 1) it theoretically identifies two criteria that parties can use to assess the electoral risks and opportunities associated with each issue; 2) it develops a synthetic index based on a combination of such criteria. ${ }^{5}$ In a nutshell, optimal issues are those where a policy position ${ }^{6}$ is: a) associated with the party (both in statistical and substantive sense), so as to provide a beneficial competitive linkage for the party and minimize the risk of internal divisions; b) widely supported in the general electorate (well beyond the current level of party support), so as to offer a potential for electoral expansion (De Sio, 2010; De Sio \& Weber, 2014). Finally, the model defines as bridge issues those issues that combine both characteristics (as they in fact represent a "bridge" allowing the party to reach out to a new, larger voter base) and predicts that such issues will receive the highest emphasis in party campaigns.

To help grasping the key mechanisms of the model, we present in Table 1 a summarization of the electoral opportunities and risks presented by different issues to the four major Italian parties, according to an original CAWI survey we administered in Spring 2014, during the 
European parliament election campaign (see below). For each policy statement, we report: a) the percentage of agreement among all respondents; b) the percentage of agreement among voters of each of the parties $;^{7} \mathrm{c}$ ) values of the issue yield index offered by each issue (separately for the pro and anti side) to each party. ${ }^{8}$

Table 1 about here

As clear from the table, values of the issue yield index offer a summarization of a positive combination of high support in general and even higher support within the party (implying a positive party-issue association). This can be effectively exemplified by contrasting the issue yield configurations for the centre-left, mainstream Democratic Party (PD) and for the rightwing, populist Northern League (Ln). Issues with the highest yield for the PD are (ranked by decreasing yield): 1) support for sustainable development (0.89); 2) support for a budget reduction for F-35 fighter-bombers $(0.88)$; 3 ) support for reduction of income inequality $(0.85)$ and 4) for EU integration $(0.85)$; 5) hostility towards allowing macro-regions to secede from Italy ( 0.84 for the anti position, in the penultimate row of the table). As an example, the high value of the index for sustainable development (0.89) reflects the high support in the general electorate $(87 \%)$ and an even higher support within the party $(93 \%)$. As a result, such issue does not present risks of internal division, and offers large opportunities for potential electoral expansion.

Similar considerations apply for the Northern League. Its configuration shows, as top issues: 1) support for a tougher attitude against India in the Enrica Lexie case $(0.98) ; 2)$ support for more restrictive laws against immigration $(0.95)$; 3) support for privileging Italians in welfare access $(0.93)$; 4) support for the legalization of prostitution (0.82) and 5) for a budget reduction for F-35 fighter-bombers (0.82). In the case of the Enrica Lexie issue, the value of 0.98 reflects 
the high support in the general electorate $(80 \%)$ and the almost unanimous support within the party $(98 \%)$. In general, it is clear that lower-yield issues, for each party, are associated with lower levels of general support and higher risks of internal divisions.

As a result, we argue that the issue yield model offers an effective way to assess the combination of risks and opportunities that each issue offers to each party. As such, it offers a model of strategic issue selection that is not constrained to specific (types of) parties. However, further elaboration is needed, in terms of the complex issue yield dynamics of multi-party systems. This is the task we now confront in our original elaboration.

\section{Issue yield dynamics in multi-party systems}

The patterns shown in Table 1 already suggest how multi-party competition presents issue competition dynamics that differ from a two-party context. In a two-party system, an issue with a high yield for a party will likely present a much lower yield for its rival: as a result, the two will mostly emphasize different issues. In a multiparty system the situation is more complex: in particular, it is likely that e.g. two parties will have a high yield on the same issue. In principle, we would expect both parties to emphasize it; in practice, however, both parties will carefully assess whether to use the issue or not, to avoid the risk that bringing the issue to the attention of voters might, in the end, favour the other party.

This problem cannot be directly addressed by the issue yield index alone, as it only takes into account one party at a time. In order to account for multiparty dynamics, we suggest to introduce two additional aspects that concern respectively: a) the relative position of a party in terms of yield on a specific issue - vis-à-vis other parties; b) the extent of issue yield differentiation among parties within the same issue. 
Regarding the first aspect, we argue that having a relatively high yield on an issue might still not be enough for a party to be motivated in strategically emphasizing that issue. A party also has to take into account its relative position vis-à-vis other parties. Having a relatively high yield might still be compatible with the presence of another party with an even higher yield. In this scenario the issue yield mechanism might be dampened, as the party would avoid emphasizing the issue, given that such emphasis might result in an electoral benefit for another party. As a result, we argue that - for a party - the issue yield mechanism will act in full force only for such issues where the party enjoys a favourable relative position (i.e. with the highest ranking yield on that issue). Therefore, the higher the relative position of a party on an issue, the higher the impact of issue yield.

As for the second aspect, it should be clear enough by comparing - in Table 1 - issue yield values for the ius soli issue (granting Italian citizenship to all babies born on Italian soil). The issue yield configuration appears clearly differentiated on this issue, ranging from a low 0.34 for Ln to a very high 0.82 for the PD, and with clearly separated intermediate values of 0.54 for Fi and 0.67 for M5S. In such a scenario, we would expect issue emphasis to reflect closely issue yield, with the PD likely emphasizing the issue and other parties presenting lower levels of emphasis. On the contrary, consider an issue such as heterologous insemination. Here values of yield for all parties are in a much narrower range (between 0.57 and 0.70 ): as a result, there is a high risk that - if one party attempts to move the public debate towards this issue - this effort might either raise an inconclusive discussion among different parties - none of which enjoys some particularly beneficial position (not even the one raising the issue) - or become counterproductive by increasing the perceived importance of an issue on which other parties could potentially intercept the support with more convincing arguments during the campaign (given that the baseline levels are close). In this case, we expect parties to avoid wasting campaign energies on such unproductive or potentially damaging issues, leading to a lower 
importance of the logic of issue yield. Conversely, and in general terms, the higher the issue yield differentiation among parties on a given issue, the higher the impact of issue yield.

\section{Hypotheses}

We finally express the aforementioned considerations in terms of empirical hypotheses. We anticipate here that (as discussed in the next section) the case study concerns the campaign for the European Parliament 2014 election in Italy, and that the parties' strategic issue emphasis will be measured through a coding of Twitter content. In light of these choices, our research questions translate into the following hypotheses:

H1: issue yield (measured pre-campaign) predicts Twitter emphasis in the campaign;

$\mathrm{H} 2$ : issue yield presents a positive interaction with the party's relative position (in terms of issue yield) on a given issue;

H3: issue yield presents a positive interaction with issue yield differentiation on a given issue.

\section{Capturing party strategy: a novel research design}

As anticipated in the Introduction, several contributions have empirically tested the theoretical predictions of the issue yield model. All of them have employed secondary analysis, thus relying on existing datasets whose data collection process was not designed with issue yield theory in mind. Thus, we argue that a newly conceived research design aimed at testing issue yield theory might improve the data collection process in the following directions:

a) Scope and number of issues. So far, applications of the issue yield model have been relying, for calculating issue yield configurations, on the European Election Study Voter Component of 2009 and 2014 (De Sio \& Weber, 2014; De Sio, Franklin, \& Weber, 2016). Such surveys only included a relatively small number of policy issue statements (12 for the EES 2009, 8 for the EES 2014), mostly aimed at capturing general orientations on broader value dimensions (economic, cultural, EU integration) than current, salient, country-specific 
campaign issues. As a result, an original research design should aim at including a larger number of policy issues, ideally covering most of the questions that are salient in the political debate in a given country (as they would become the strategic resources employed by parties during the campaign).

b) Operationalization of the dependent variable. The aforementioned applications have operationalized party emphasis on different issues through Manifesto data. This poses at least two concerns. First, in general party manifestos are actually recognised to not fully represent the strategic communication employed by parties for electoral purposes. Not only manifestos inevitably reflect the compromises related to intra-party conflicts (and the need to accommodate the requests of party ideologists), but - most importantly - they inherently run in a logic that is much different compared to the issue yield model. While the model posits that parties will focus on a relatively small number of strategic issues, party manifestos aim at covering many issues across different policy domains, in order to supply members and militants with the official position of the party. This logic is not fully compatible with the kind of strategic emphasis described by the issue yield model. Second, Manifesto data introduce an additional difficulty. Issue yield configurations (the main predictor) are measured by assessing public opinion on specific policy statements, while issue emphasis (the outcome) is measured as the proportion of a party manifesto that is devoted to a particular content category. Such categories are relatively broad, and with no specific connection to actual survey statements. As a result, a stage of conceptual matching, assessing which Manifesto category can be associated with a survey statement, is required. Such process yields matchings of variable quality: while some statements very closely match a Manifesto category, some often do not.

c) Time sequence of data collection. Issue yield studies so far have mostly computed the main predictor (issue yield) from post-electoral surveys, and the outcome (issue emphasis) from pre-electoral manifestos. Such studies have properly acknowledged this paradox, preventing 
any causal interpretation, and arguing that in fact both measures were capturing the effect of latent issue yield configurations; however, a proper design should attempt at measuring the predictor and the outcome by collecting data with an appropriate time sequence.

In light of these concerns, we developed a novel research design. Among others, the main distinguishing feature of the design is in the selection of Twitter content to capture the strategic communication choices performed by political parties. Among the possible alternatives for capturing parties' strategic issue emphasis choices, social media represent nowadays an interesting possibility. In a way, they represent perhaps the most widely accessible form of party communication, with party leaders increasingly aware of their power.

There are good reasons why party communication on Twitter might follow strategic considerations, much more than Manifesto data: given the much higher temporal adaptability and interaction potential of Twitter content (compared to party manifestos) for shaping the actual electoral campaign (Graham, Broersma, Hazelhoff, \& Haar, 2013), we expect a party to see Twitter as an ideal tool to emphasize the issues presenting the highest electoral potential.

This is not only due to the potential for direct party-voter interaction on the social media, but - perhaps most importantly - to a potential for indirect interaction, deriving from the systematic use that journalists (and other politicians) make of the official Twitter accounts of political parties and leaders to learn about their political messages, or for directly broadcasting politicians' tweets to a much wider and more traditional audience. As a consequence, Twitter is also increasingly attracting the interest of political behaviour scholars (Barberá, 2015; Dubois \& Gaffney, 2014; Vaccari et al., 2013). Therefore we argue that the content diffused through political parties' Twitter accounts might be effectively used to capture their strategic political communication. However, our choice is conditional on a necessary theoretical assumption, which we label as the press-release assumption: regardless of how many followers (and of which type) a party's Twitter account might have, and regardless of how unrepresentative and 
elitist the Twitter audience might be in a given country, we assume that parties will use Twitter anyway to communicate their desired messages to the media, just like in a press release; the appropriateness of this assumption appears well supported by previous empirical research (Parmelee \& Bichard, 2011; Verweij, 2012; Parmelee, 2013; Kreiss, 2016). As a result, we deem party communication on Twitter a valid indicator of their actual strategic priorities.

Indeed, this identifies party communication on Twitter as a privileged field to test the predictions of issue yield theory: while party manifestos represent an excellent source to measure the underlying ideological stances, they may not fully capture short-term strategic emphases that characterize contemporary campaigns. Also, while manifestos often contain compromise choices related e.g. to different groups within a party, Twitter can be expected to effectively capture the genuinely strategic component of party communication (Nooy \& Kleinnijenhuis, 2013; Shaw, 2006).

As a result, the newly proposed research design - aimed at addressing the above concerns - features three main stages.

(a) a pre-electoral selection of a large number of potentially relevant issues. This should ideally be performed without constraints on the number of issues, and with the purpose of covering all issues that might potentially be employed during the coming campaign; (b) a voter survey, based on a questionnaire including items for all the previously identified issues, aimed at capturing the issue yield configurations for each party before the campaign. The collected data should allow to compute the main predictor, the issue yield of each positional issue for each party (issue yield calculation only requires a positional item for each issue, and a separate item for party preference);

(c) the collection and coding of Twitter content for each party during the campaign (according to a coding scheme covering exactly the same issues identified in step (a)), in order to properly capture the strategic campaign choices by political parties. Ideally, 
tweets should be separately coded by at least two independent coders, in order to assess inter-coder reliability of the coding scheme. The coding procedure requires coders to assign each tweet either to one of the previously identified issues, or to a residual "other issue" category, or to a "non-issue content" category.

A data collection process performed according to the aforementioned stages allows, in our view, a more rigorous empirical assessment of the theoretical predictions formulated by the issue yield model.

\section{A pilot study}

We proceeded to implement a pilot study for this research design, at the occasion of the 2014 EP elections in Italy. ${ }^{9}$ As a preliminary assessment of the relevance of Twitter communication in Italy (at least in terms of the validity of the press-release assumption), we report that the number of Italian Twitter users reached 8.9 million in December 2014. All Italian political parties and party leaders make a systematic use of Twitter accounts at campaign time, and the media comment on political leaders' tweets on a daily basis.

The first stage (issue identification) led our team to identify 23 positional statements, ranging from economic issues (tax evasion, income inequality, unemployment benefits) to social issues (civil partnerships, abortion) to issues specifically related to the European Union (EU integration, Euro). Actual question wordings for all issues can be found in Table A1 in the Appendix. ${ }^{10}$

Second, we fielded the questionnaire through a pre-electoral CAWI (Computer Assisted Web Interviewing) survey $(\mathrm{N}=1608) .{ }^{11}$ The data collected allowed us to compute the main predictor, the issue yield of each positional issue for each party ( 8 parties and 23 issues for a 
total of 184 observations $^{12}$ ), at the correct point in time, i.e. based on pre-electoral data. As previously stated, such yield is hypothesized to predict Twitter emphasis on the same issues.

Third, we collected all tweets for the official accounts of the main Italian parties and their leaders ${ }^{13}$ during a campaign window of 21 days. ${ }^{14}$ Then, all tweets were manually coded by two independent coders, required to assign each tweet to one of the aforementioned issues, or to classify them as either dedicated to other issues or to non-issue content. As reported in Table 2, Cohen's Kappa statistic, measuring inter-rater agreement, gives a value of $0.80 .{ }^{15}$ After checking inter-rater agreement, one of the two coders was preferred for the slightly higher number of tweets classified as issue content. Such classification of tweets has allowed the final computation of the outcome, i.e. parties' Twitter emphasis on each issue.

Table 2 about here

Our pilot implementation of the proposed research design allowed, in our view, to address the concerns expressed at the beginning of this section. First, we were free to include a relatively large number of issues, in fact covering all the main issues that parties would later employ in the campaign. Secondly, the manual coding procedure benefited substantially from the lack of a conceptual matching stage: the guide for coders was not represented by general category coding guidelines to be then linked to survey statements (such as when using Manifesto data) but by the survey statements themselves. Finally, the measurement of issue yield configurations in pre-electoral data goes in the direction of addressing the above concern related to the time sequence of the data collection. The data collection process we achieved is not a full implementation of the research design, as the timeframes of both the predictor and the outcome are still in fact coincident; however, this already represents a substantial improvement 
compared to previous applications, where data for the outcome were collected before data for the predictor.

\section{Modelling choices and statistical issues}

In addition to the general characteristics of the research design, there are few additional technical considerations related to the operationalization of specific indicators, as well as the choice of an appropriate statistical method for model testing.

\section{Modelling multiparty competition}

As anticipated in the theoretical section, interparty influences on political communication can be described in terms of the relative position of a party - in terms of issue yield - on a given issue and of the issue yield differentiation on a given issue. The relative position of political parties in terms of issue yield is operationalized by rescaling - within each issue, for all parties - the yield to vary between 0 and 1 , where 0 is assigned to the minimum observed level of issue yield on that specific issue, 1 to the maximum observed value, and all intermediate values rescaled accordingly to intermediate values. As a result, the party with the highest yield on an issue will score 1 , the party with the lowest yield will score 0 , and other parties will score intermediate values. This effectively captures the relative issue yield position of the party on each issue. ${ }^{16}$ Issue yield differentiation is instead operationalized by looking - for each issue at the range between the maximum and the minimum issue yield values registered for different political parties on the same issue. Figure A1 in the Appendix presents the distribution of this issue-level indicator.

Therefore, we model the emphasis assigned by political parties to issues as depending on issue yield, our main predictor, as well as by its interaction with the two aforementioned aspects of multiparty competition. In particular, we expect both the interaction coefficients between the multiparty competition variables and the yield variable to be positive: on the one hand, we 
expect political parties who are higher in the ranking of issue yields to display a stronger effect of issue yields on issue emphasis. In fact, having the greatest yield on a certain issue implies that the party is very strongly associated with the issue, and thus the return for emphasizing it will be higher than for other parties.

On the other hand, a greater range between the minimum and maximum issue yield implies that the specific issue is less competitive (some parties will clearly avoid the issue), and again the parties with the higher yield are more clearly advantaged by its emphasis. When such range is smaller, it means that the highest and lowest issue yields are closer to each other, and therefore emphasizing that issue might not result in a productive strategy for political parties. ${ }^{17}$

\section{Twitter emphasis as censored data}

Are political parties' tweets resulting from strategic computations that can be predicted by the issue yield model or, rather, do they represent erratic expressions detached from the underlying dynamics in public opinion? Different answers to this question have important implications for correctly modelling our dependent variable, and this requires few additional considerations.

In the first place, issue emphasis in our study is measured by the proportion of tweets that have been assigned to issue categories. This implies that the dependent variable represents a proportion: as a result, it is constrained between 0 and 1 . Moreover, the distribution of tweets is strongly asymmetrical, with a large majority of party-issue combinations (71.2\%) presenting

no tweets at all (see Figure A2 in the Appendix). ${ }^{18}$, In this case, predictions from a linear model are likely to fall outside of the zero threshold, producing logically impossible expectations of negative emphasis. This will also decrease variance, as values of the dependent variable approach 0 , leading to an underestimation of the uncertainty in our inferences. For all these reasons, OLS regression might not be appropriate. We chose then to treat the proportions as a distribution censored in $0 .{ }^{19}$ This corresponds to the idea that parties would decrease emphasis 
even below zero, if that would be possible, for issues that are really unfavourable; while, in principle, some issues would receive an actual zero emphasis as they are simply not considered very relevant to be mentioned. As a result, the dependent variable might be considered (following previous applications) as censored at 0 , thus leading to the choice of a Tobit model, which we adopt for our analysis. As a result, the estimated Tobit model is the following:

$$
\begin{aligned}
& \text { Emph }_{i j}=\alpha+\beta \text { Yield }_{i j}+\gamma \text { Yield }_{i j} \cdot \text { Rel }_{i j}+\delta \text { Yield }_{i j} \cdot \text { Diff }_{j}+\boldsymbol{\theta} \boldsymbol{X}+\varepsilon_{i j} \\
& \text { Emph }_{\mathrm{ij}}=\left\{\begin{array}{c}
\mathrm{y}_{\mathrm{ij}}^{*} \text { if } \mathrm{y}_{\mathrm{ij}}^{*}>0 \\
0 \text { if } \mathrm{y}_{\mathrm{ij}}^{*} \leq 0
\end{array}\right.
\end{aligned}
$$

where $i$ indexes the political parties and $j$ the policy issues, and the dependent variable $E m p h_{i j}$ is modelled as censored at 0. Yield $_{i j}$ indicates the computed index of issue yield for party $i$ on policy issue $j$; $\operatorname{Rel}_{i j}$ stands for the relative position of the political party in the specific issue; and $\operatorname{Diff} f_{j}$ refers to the issue differentiation component of multiparty competition. The quantities of interest are $\beta, \gamma, \delta$ and are expected to be greater than 0 . All the main terms of the interactions have been included in $\boldsymbol{\theta} \boldsymbol{X}$ to facilitate readership; $\boldsymbol{y}_{i j}^{*}$ is the unobserved uncensored variable; $\varepsilon_{i j}$ is a stochastic component clustered within parties.

\section{Descriptive statistics and empirical results}

Before moving to the empirical analysis and hypotheses testing, it is useful to present some descriptives related to the positional issues included in the analysis, and to the emphasis parties put on them. Table 3 reports, for each party ${ }^{20}$, the total number of tweets coded as positional issues. The table also includes the total number of tweets coded as valence issues (albeit not analysed here), the total number of tweets related to non-issue content, and finally the total 
number of tweets made during the 21 days of electoral campaign under analysis. As can be easily noted, the total number of tweets coded as issues (both positional and valence) represents only about a third of the total number of tweets made by the official accounts of parties and their leaders during the campaign (942 out of 2832). It follows that about two thirds of the tweets (1890) were actually dealing with the campaign dynamics, often mentioning other political actors rather than more substantive topics. ${ }^{21}$ The ratio between issue and non-issue content is even more unbalanced as concerns the M5S, where as high as $83.6 \%$ of the total tweets are not related to issues. This finding should not come as a surprise as it is one of the earliest findings of political communication research, going back to the work of the Columbia School: "The most talked-about subject matter during the campaign was the campaign itself" (Lazarsfeld, Berelson, \& Gaudet, 1944, p. 115).

Table 3 about here

Focusing on positional issues, a first key finding is the large variability in the absolute number of tweets produced by each party on positional issues: it ranges from only eight tweets produced by the extreme-left party list "Other Europe with Tsipras" (and its leader Nichi Vendola) to 192 produced by Forza Italia and its leader Silvio Berlusconi. Notwithstanding the emphasis pundits and commentators usually put on the ability of Beppe Grillo and his M5S, as well as of Matteo Renzi, on the use of social media for political communication, the campaign of the two main Italian parties, PD and M5S, is characterized by a lower number of tweeted messages compared to other parties and particularly to those belonging to the centre-right bloc: Forza Italia and the Northern League together cover $61 \%$ of all positional tweets coded. Therefore, Italian parties follow different strategies on Twitter, either selecting a few number of tweets (about one for each day of the campaign) that emphasize the position of the party on 
a given issue or flooding the potential audience with a massive number of tweets (more than 9 per day as regards Forza Italia), often repeating the same tweet more than once during the same day or in following days. ${ }^{22}$

But the most important piece of evidence (and a first striking confirmation of the dynamics theorized by the issue yield model) emerges from Table 4, which illustrates the frequency distribution of tweets across issues and parties. Overall, out of the 184 possible cells (23 issues for 8 parties) only 53 were actually filled. This means that, on average, each party focuses on only about seven issues during the campaign (from a minimum of 5 for 'Other Europe with Tsipras' to a maximum of 9 for Forza Italia). Moreover, while some issues are only mentioned by a single party, such as sustainable development (owned by the M5S), others are mentioned by several parties (like immigration or Renzi's institutional reforms). We have already noted the large variation in the number of tweets made by each party during the campaign. A similar variation occurs as far as issues are concerned: out of the 23 issues selected by the research team as potentially relevant for the campaign, only 16 have actually received attention by parties, while seven have been completely ignored. Moreover, among the 16 issues on which parties have put at least some emphasis, we find a large number of issues with a few tweets only (11 issues range between 4 and 18 tweets), while six receive larger attention, with more than 20 tweets across the 21 days of campaign.

It is worth examining what are the issues that receive most overall attention, although this finding is potentially biased by the disproportionate tendency of some parties to tweet much more than others. The most important policy areas on which parties focus are immigration, Europe, Renzi's institutional reforms and economic redistribution. The most tweeted issue is immigration (107 tweets), receiving a large emphasis especially from the two opposition parties that share the most negative views on immigrants: the Northern League and Brothers of Italy, for which this issue accounts, respectively, for $39 \%$ and $32 \%$ of their positional tweets. Not 
by chance, Northern League and Brothers of Italy are by far the two parties with the highest yield on this issue (0.95 and 1 respectively). Considered together, the two issues of EU integration and exit from the Euro area are the most salient during the campaign, with 185 tweets: this finding could be considered surprising, given that one of the assumption of the second-order election theory is that the campaign is usually dominated by national issues (Reif and Schmitt 1980). However, this is mostly due by the tweet-prolific style of FI and LN. In general, parties that have a positive stance towards Europe usually focus on EU integration (the overall majority of tweets on this issues come from European Choice that has a very high yield on this issue, 0.88), while the issue related to the possible exit from the Euro area is owned by the Northern League (80 tweets out of 94) that carried out a heated campaign against the single currency. The issue of Renzi's institutional reform is only partially exploited by Renzi and the PD (16\% of their tweets are on this issue) but it becomes the main issue - negatively emphasized by the M5S. On the contrary, Renzi's party choses to focus on the reduction of income inequality (42\% of its tweets are on this issue) given the fiscal bonus of 80 euro provided by the government to low-income people just before the start of the electoral campaign. Another very important issue is related to the controversy emerged within the centerright bloc about the supposed "betrayal" of Alfano (the leader of New Center-right, NCD) against Berlusconi: not surprisingly, the only parties to mention this issue are the two ones involved in the controversy, namely Forza Italia (28 tweets) and NCD (29 tweets). Furthermore, note that 72 tweets have been classified as "other issues", since they deal with positional issues falling outside the 23 surveyed ones ${ }^{23}$.

Table 4 about here 
Exploring the data, we have already pointed out a number of relevant empirical findings, and most importantly, we have implicitly assessed at face validity our measure of Twitter emphasis. We can finally proceed with the empirical testing of the three hypotheses presented in the second section. In particular, we want to test whether the emphasis that parties place on the policy issues is predicted by issue yield, and secondly whether the influence of other parties' strategies can be effectively modelled through our two indicators related to multi-party competition.

\section{Testing the hypotheses}

In Table 5, we present estimations of tobit models of Twitter emphasis, according to three different empirical specifications. In model (1), we model Twitter emphasis on issue yield; in model (2), we add the party's issue yield relative position on that issue; finally, in model (3) we estimate the full theoretical model, including issue yield differentiation on that issue. The results are striking. The coefficient for issue yield is positive and statistically significant: as a result, Hypothesis 1 is confirmed: issue yield (measured before the campaign) is a predictor of Twitter emphasis of specific issues during the campaign, with a remarkable and statistically significant effect (and with a pseudo- $\mathrm{R}^{2}$ of 0.09$)^{24}$. The second model's specification adds the relative component. The presence of a positive and significant interaction between issue yield and the Rel variable (relative position) confirms Hypothesis 2. The better the party ranking on the issue, the stronger the effect of issue yield. Such result (even clearer from the marginal plots reported below in Figure 1) in fact shows that issue yield has no effect on tweets' proportions for those issues where the party - compared to other parties - has the lowest level of issue yield. The result is reasonable, because when a party has the lowest yield on an issue compared to other parties, then emphasizing it (regardless of the low or high value of yield) will be counterproductive, ending up favouring a competitor. But for higher values of the Rel variable 
(relative position) the effect of issue yield becomes positive and significant. Moreover, when adding this component of multiparty competition the pseudo- $\mathrm{R}^{2}$ increases up to 0.14 . These findings are a clear confirmation for Hypothesis 2.

Table 5 about here

Finally, the main specification includes both components of multiparty competition. Here, again, the presence of a positive and significant interaction between issue yield and our differentiation index clearly confirms Hypothesis 3: issue yield dynamics are effective for issues where parties are clearly differentiated ${ }^{25}$. However, it has to be considered that models are nonlinear. Therefore, we can only have indications regarding the presence and the sign of the relationships, because coefficients represent the marginal effect on the latent uncensored dependent variable $\left(\beta=\frac{\partial E\left[y^{*} \mid x\right]}{\partial x}\right)$. Furthermore, it is opportune to estimate the effect of the covariates on the censored distribution: $\beta \cdot \Phi(x \beta)=\frac{\partial E[y \mid x, y>0]}{\partial x}$. In this case, the marginal effect of issue yield on the number of tweets for a certain issue ranges from -0.12 when issue yield is equal to its minimum (Yield $=0.294$ ) and +0.14 , for its maximum $($ Yield $=1$ ). To better assess the magnitude of the relations, especially because the three measures are modelled interactively, we also provide a graphical representation of the marginal effects in the following Figure 1.

On the left pane, the figure shows that the effect of issue yield on Twitter communication is conditional on the parties being enough differentiated on a given issue. Specifically, issue yield presents positive and significant effects only for levels of issue differentiation above 0.45 (approximately). This for example corresponds to an issue where the top party on that issue has a yield of 0.90 and the worst party has a yield of 0.45 . Thus, parties systematically tend to emphasize a topic only insofar as issue opportunities are clearly differentiated among parties 
on that issue, so that the advantaged parties are rather certain about the potential electoral return. Otherwise, parties refrain from emphasizing issues where - regardless of the yield level - other parties have similar yields, thus with the risk of being benefited by the party's emphasis. This result provides supporting evidence for Hypothesis 3: issue yield dynamics are relevant on issues where parties' yields are sufficiently differentiated.

Figure 1 about here

The graph on the right pane finally shows how the effect of issue yield on Twitter issue emphasis increases for those parties with the highest issue yield ranking on that topic. Our interpretation of this finding is that political parties are only sensitive to issue yield for those issues where they rank highest (this corresponds to a relative position of 0.8 or higher, in fact mostly corresponding to ranking first or second on the issue); otherwise they become indifferent to issue yield, as an emphasis could advantage some other party. ${ }^{26}$

Finally, the aforementioned effects of issue yield (with the moderating effect of relative position and differentiation) are perhaps best exemplified by looking at the predicted probabilities that a party will tweet at least once on a specific issue, based on its issue yield configuration. When computing such probabilities for different scenarios,${ }^{27}$ one understands the importance of issue yield. For example, comparing two issues with low $(<0.4)$ and high $(>$ 0.9) yield, probability of nonzero party twitting on the issues goes from $18 \%$ to $58 \%$. For issues with average yield ( 0.55 to 0.85 , corresponding to the mean plus or minus one standard deviation), a party ranking first will have a twitting probability of $41 \%$, while a party ranking last will have a probability of $14 \%$. Finally, for issues with high yield (>0.9), the probability is $38 \%$ when party differentiation is low (issue yield for all parties in a range of 0.25 or lower), 
while it jumps to $78 \%$ when party differentiation is high (issue yields in a range of 0.64 or larger).

Overall, we find that issue yield theory is clearly confirmed by this empirical exercise, and with an important explanatory contribution provided by our two innovative measures of multiparty competition dynamics.

\section{Conclusions}

The main goal of this paper was the theoretical elaboration of the issue yield model for multiparty competition contexts, along with the introduction of a novel research design, aimed at testing the issue yield model by overcoming some of the limitations of previous studies. In particular, the crucial innovation was twofold: the introduction of a framework for multi-party competition; and the adoption of Twitter content for measuring the outcome, i.e. the issue emphasis employed by different parties on different issues. As for the first aspect, our discussion and operationalization of multi-party dynamics, leading to the introduction of the concepts of issue yield relative position and issue yield differentiation, appear valid and empirically supported. Indeed, the performance of the model significantly improves when specifically calibrated by taking into account the complex dynamics of multi-party competition, as expressed by our newly introduced measures.

Secondly, results confirm the validity of the research design, in two regards. First, issue yield dynamics are clearly relevant even in Twitter communication: issue yield is a significant predictor of Twitter issue emphasis, also providing a non-trivial amount of variance explained. Also, the clear asymmetries between parties in the emphasis dedicated to different issues testify the clearly strategic dynamics that characterize party communication on Twitter. Additionally, a very important finding concerns the very possibility of developing a coding scheme for matching Twitter content to positional issue statements. Results are impressively positive: 
despite the complexity of the scheme, independent coders with no particular previous training were able to reach extremely high levels of inter-coder reliability. This yields a very optimistic scenario for the replication of this design in new contexts, and suggests the soundness of this research design.

However, we argue that the contribution of this paper is of mostly substantive interest, in times of an increasing presence of parties that challenge existing party system structures by relying on specific issue packages. Building on the issue yield model (which adopts a dynamic and strategic view of the issue agenda, compared to the static view of previous frameworks), our contribution not only introduces a realistic model of multi-party dynamics, but also develops an empirical research framework which is able - unlike previous applications of the issue yield model - to effectively capture even the short-term dynamics of issue competition (and perhaps even the presence of opportunities not yet exploited by any party). As a result, we argue that the future replication of our design across more elections and countries could provide breakthrough insights into the innovative issue competition strategies adopted by both mainstream and challenger parties. This in turn could lead to a realistic view of how party competition is evolving in these turbulent times.

\section{Notes}

\footnotetext{
${ }^{1}$ In the example reported by Stokes (1963), Eisenhower in 1952 decided to campaign on "Korea, Communism, and Corruption" - where he could claim far superior credibility - while avoiding a spatial, Downsian strategy on the left-right dimension. Given the overwhelming support of Americans for New Deal policies, this latter would have likely resulted in defeat.

${ }^{2}$ Such model would of course only cover the strategic component of the party system agenda, still leaving a role for systemic salience (Steenbergen \& Scott, 2004; Wagner, 2012).

${ }^{3}$ Recent applications of issue ownership theory have mostly adopted survey-based, more dynamic measures of issue ownership, usually through items capturing party competence on a list of shared goals (Walgrave, Lefevere, \& Tresch, 2012, pp. 781-84). However, these strategies still assume an underlying valence
} 
logic which hardly generalizes to positional issues (especially relevant in multi-party systems). This potential limitation is somehow also present in innovative approaches such as associative issue ownership (ibidem).

${ }^{4}$ The authors explicitly define issue entrepreneurship as "the ... mobilization of a previously ignored and not divisive issue [on] ... a policy position ... substantially different from the status quo position of the mainstream" (Hobolt \& De Vries, 2015, p. 1163).

${ }^{5}$ Departing from the Downsian model, the issue yield model assumes that parties will mostly attempt not to change their policy positions, as this move is often costly and difficult. The model instead posits that a party disadvantaged on some issue will downplay its importance and turn to other issues where it enjoys a more favorable position.

${ }^{6}$ Party positions are operationalized in dichotomous form (for or against a given policy).

${ }^{7}$ Identified through vote intention.

${ }^{8}$ The index is calculated according to a non-linear expression. Let $p$ be the percentage of respondents supporting a party; $i$ the percentage approving a policy statement, $f$ the percentage jointly supporting the party and approving the statement; then the issue yield index is expressed by yield $=\frac{f-i p}{p(1-p)}+\frac{i-p}{1-p}$ (De Sio and Weber 2014, 876-878).

${ }^{9}$ Our choice of selecting an EP election is not specifically related to EU politics, but relying on the approach of considering EP elections as "windows into national political processes" (Van der Eijk \& Franklin, 1996; Brug, Eijk, \& Franklin, 2007; De Sio \& Franklin, 2012). Based on the consensus over EP elections as "second-order" elections, we deem that this selection does not introduce significant biases in terms of testing our multi-party model, as EP campaigns tend to be dominated by domestic issues (as was the case for Italy in 2014: see De Sio, Emanuele, \& Maggini, 2014).

${ }^{10}$ The questionnaire also included credibility items for 17 valence issues, not analysed here, but included in the Twitter coding scheme.

${ }^{11}$ CAWI fieldwork took place between April 29 and May 9, 2016, on a sample of the adult population resident in Italy (response rate was 25.9\%). Respondents were extracted - according to a quota sampling by sex, age and geographical area - from a Web respondent community. Results reported here (except for the final models) were then weighted by stratification variables, plus level of education, political interest and past party vote recall. As suggested by Pasek (2016), an online survey relying on a non-probability sample may provide imperfect estimates of the frequencies of politically relevant variables. This is confirmed by e.g. frequency distributions for political interest in our sample with a well-known and widely-used probability sample, the 2013 CAPI survey from the ITANES (Italian National Election Studies). The two distributions show significant differences, with very interested and fairly interested representing $75 \%$ of respondents in our survey vs. $37 \%$ according to ITANES, and a reported turnout of $85.5 \%$ vs. the actual $58.7 \%$. However, such large differences in political interest do not translate in equally large differences in the main quantities of interest. When comparing unweighted with weighted data (with our weight also including political interest), support for specific policies (both at large and within each party) only differs by few percentage points, so that a final robustness check we performed (replicating our final models on both weighted and unweighted data) yields fully equivalent results (available on request). 
${ }^{12}$ The total number of observations for issue yield is 368 , since each issue has two sides (pro or anti). The final number of observations is $184(368 / 2)$ because we assume the optimal side is chosen (the one with the highest yield).

${ }^{13}$ We coded tweets from official accounts of the following parties and leaders: Democratic Party (PD), Five Star Movement (M5S), Forza Italia (FI), Northern League (LN), New Center-right (NCD), Other Europe with Tsipras (TSIPRAS) and European Choice (SE); and from official accounts of the following leaders: Matteo Renzi (PD), Beppe Grillo (M5S), Silvio Berlusconi (FI), Giorgia Meloni (Brothers of Italy, FDI), Angelino Alfano (NCD), Nichi Vendola (TSIPRAS) and Andrea Romano (SE). A party account did not exist for FDI, while a leader account did not exist for Matteo Salvini (LN). In both cases, we coded party communication from the other available account (Giorgia Meloni and Northern League).

${ }^{14}$ Twitter content was collected between April 14 and May 4, covering between 6 and 3 weeks before the vote.

15 Fleiss (1981)'s guidelines to interpret the meaning of the kappa statistic consider values over 0.75 as excellent. Kappa values were calculated on a 40 -issue coding scheme that included both the 23 positional issues and the 17 valence issues (not analyzed here).

${ }^{16}$ Such rescaling to 0-1 eliminates between-issue differences in issue yield differentiation, which are separately captured by the previous index. As a result, we can separately assess these two distinct conceptual aspects.

${ }^{17}$ While developing our multi-party extension of the issue yield model, we also explored alternative explanations, with special regard to the relevance of systemic salience (Steenbergen \& Scott, 2004; Kaplan, Park, \& Ridout, 2006; Wagner, 2012) and of a more classic operationalization of issue ownership. Results of these explorations, which confirm the validity of our model, are reported in the Appendix, and briefly mentioned below in terms of robustness checks.

${ }^{18}$ This is not surprising, and indeed a confirmation that parties tend to concentrate their emphasis on a relatively small number of issues among all the potential issues available.

${ }^{19}$ Another possibility is to fit a linear model on the logit transformation of the dependent variable (Papke \& Wooldridge, 1996). However, this would exclude 0s and 1s, which would require a separate treatment. This problem appears relevant, as 0s are the mode of the distribution. For the same reason, tweets' proportions cannot be modeled through a beta distribution.

${ }^{20}$ Each row represents the sum of the official account of the party and that of the respective party leader.

${ }^{21}$ In any case, coders were clearly instructed to code as issue-related all tweets that presented issue content, regardless of the presence of references to other actors.

${ }^{22}$ In a way, the relatively sparse communication style of some parties is a confirmation of the press release assumption: under strong media attention, even a single daily tweet will have a very large media impact.

${ }^{23}$ Indeed, note that all the 72 tweets classified as "other issues" were about the classic taxes/public services trade-off, which - in this particular framing - we did not include in our classification scheme. However, this represents a confirmation of the overall validity of our ex-ante issue selection, given that only one relevant issue was not included in the scheme.

${ }^{24}$ We performed additional robustness checks. In particular, we controlled for systemic issue salience by relying on a convenience operationalization first used by Bartels (1986), based on the number of missing responses on issue stances (capturing the inverse of issue salience). The results (Table A2 in the Appendix) are 
reassuring, showing a positive and significant effect of systemic issue salience but still leaving the results of our model fundamentally unchanged. We also controlled for the effect of issue ownership by introducing a dichotomous variable where issues that are unambiguously owned by a given party are coded 1 , and all the remaining issues are coded 0 (party-issue pairings available on request). The effect of issue yield remains significant even when we control for issue ownership (Table A3 in the Appendix). Moreover, we performed a leave-one-out test by re-running the analyses reported in Table 5 excluding one party at a time and one issue at a time (for our 23 positional issues and 8 parties). The results are substantially identical to those reported in Table 5 (results available upon request).

${ }^{25}$ The results appear clearly robust, as they hold even if we model the issue emphasis with simple OLS regression, or even with a mixture of a beta distribution (modeling the internal values) and a Bernoulli distribution (to inflate the 0s). This latter specification would correspond to a more articulated decision process (Ospina \& Ferrari, 2012), separating which issues to emphasize from how much to emphasize them.

${ }^{26}$ The presence of apparently negative effects of issue yield for extremely low values of Rel emerges from issues of parametric extrapolation of the simplified multiplicative interaction (such effects mostly disappear when modelling the interaction through dummies for different levels of $R e l$ ), combined with distributional considerations arising from the correlation between the two variables that are interacted (yield and $R e l$ ). In particular, combinations of very high yield with very low values of Rel would only materialize in presence of almost unanimous issues, where issue yield values would lose most of their meaning.

${ }^{27}$ We computed the probabilities that tweets' proportions for each party-issue pair are larger than zero, by fixing values of issue yield, differentiation and relative support at specific, meaningful values. 


\section{References}

Aardal, B., \& van Wijnen, P. (2005). Issue Voting. In J. Thomassen (Ed.), The European Voter (pp. 192-212). Oxford: Oxford University Press.

Alvarez, R. M., \& Nagler, J. (1995). Economics, Issues and the Perot Candidacy: Voter Choice in the 1992 Presidential Election. American Journal of Political Science, 39(3), 714-744. https://doi.org/10.2307/2111651

Alvarez, R. M., \& Nagler, J. (1998). Economics, Entitlements, and Social Issues: Voter Choice in the 1996 Presidential Election. American Journal of Political Science, 42(4), 1349-1363. https://doi.org/10.2307/2991862

Barberá, P. (2015). Birds of the Same Feather Tweet Together: Bayesian Ideal Point Estimation Using Twitter Data. Political Analysis, 23(1), 76-91. https://doi.org/10.1093/pan/mpu011

Borre, O. (2001). Issue voting: an introduction. Aarhus: Aarhus University Press.

Brug, W. van der, Eijk, C. van der, \& Franklin, M. N. (2007). The economy and the vote: economic conditions and elections in fifteen countries. Cambridge: Cambridge University Press.

Budge, I. (2015). Issue Emphases, Saliency Theory and Issue Ownership: A Historical and Conceptual Analysis. West European Politics, 38(4), 761-777. https://doi.org/10.1080/01402382.2015.1039374

Budge, I., \& Farlie, D. J. (1983). Explaining and Predicting Elections: Issue Effects and Party Strategies in Twenty-three Democracies. London: Allen \& Unwin.

Carmines, E. G., \& Stimson, J. A. (1980). The Two Faces of Issue Voting. The American Political Science Review, 74(1), 78-91. https://doi.org/10.2307/1955648 
Chiaramonte, A., \& Emanuele, V. (2015). Party system volatility, regeneration and deinstitutionalization in Western Europe (1945-2015). Party Politics, 1354068815601330. https://doi.org/10.1177/1354068815601330

De Sio, L. (2010). Beyond "position” and "valence”. A unified framework for the analysis of political issues (Working Paper). Retrieved from http://cadmus.eui.eu/handle/1814/14814

De Sio, L., Emanuele, V., \& Maggini, N. (Eds.). (2014). The European Parliament Elections of 2014. Rome: CISE. Retrieved from http://eprints.luiss.it/1344/

De Sio, L., \& Franklin, M. N. (2012). Strategic Incentives, Issue Proximity and Party Support in Europe. West European Politics, 35(6), 1363-1385. https://doi.org/10.1080/01402382.2012.713750

De Sio, L., Franklin, M. N., \& Weber, T. (2016). The risks and opportunities of Europe: How issue yield explains (non-)reactions to the financial crisis. Electoral Studies. https://doi.org/10.1016/j.electstud.2016.06.006

De Sio, L., \& Weber, T. (2014). Issue Yield: A Model of Party Strategy in Multidimensional Space. American Political Science Review, 108(04), 870-885. https://doi.org/10.1017/S0003055414000379

Dubois, E., \& Gaffney, D. (2014). The Multiple Facets of Influence: Identifying Political Influentials and Opinion Leaders on Twitter. American Behavioral Scientist. https://doi.org/10.1177/0002764214527088

Franklin, M. N. (1985). Assessing the rise of issue voting in British elections since 1964. Electoral Studies, 4(1), 37-56. https://doi.org/10.1016/0261-3794(85)90030-7

Franklin, M. N., Mackie, T. T., \& Valen, H. (1992). Electoral change. Cambridge: Cambridge University Press. 
Fuchs, D., \& Klingemann, H.-D. (1989). The Left-Right Schema. In M. Kent Jennings \& J. W. van Deth (Eds.), Continuities in Political Action (pp. 203-234). Berlin: de Gruyter.

Graham, T., Broersma, M., Hazelhoff, K., \& Haar, G. van 't. (2013). Between Broadcasting Political Messages and Interacting with Voters. Information, Communication \& Society, 16(5), 692-716. https://doi.org/10.1080/1369118X.2013.785581

Green-Pedersen, C. (2007). The Growing Importance of Issue Competition: The Changing Nature of Party Competition in Western Europe. Political Studies, 55(3), 607-628. https://doi.org/10.1111/j.1467-9248.2007.00686.x

Heath, A. F., Jowell, R., \& Curtice, J. (2001). The rise of New Labour party policies and voter choices. Oxford [UK]; New York: Oxford University Press.

Hernández, E., \& Kriesi, H. (2016). The electoral consequences of the financial and economic crisis in Europe. European Journal of Political Research, 55(2), 203-224. https://doi.org/10.1111/1475-6765.12122

Hobolt, S. B., \& De Vries, C. E. (2015). Issue entrepreneurship and multiparty competition. Comparative Political Studies, 48(9), 1159-1185.

Kaplan, N., Park, D. K., \& Ridout, T. N. (2006). Dialogue in American Political Campaigns? An Examination of Issue Convergence in Candidate Television Advertising. American Journal of Political Science, 50(3), 724-736. https://doi.org/10.1111/j.15405907.2006.00212.x

Kreiss, D. (2016). Seizing the moment: The presidential campaigns' use of Twitter during the 2012 electoral cycle. New Media \& Society, 18(8), 1473-1490. https://doi.org/10.1177/1461444814562445

Lazarsfeld, P. F., Berelson, B., \& Gaudet, H. (1944). The people's choice. New York: Columbia University Press. 
McCombs, M. E., \& Shaw, D. L. (1972). The agenda-setting function of mass media. Public Opinion Quarterly, 36(2), 176-187.

Meguid, B. M. (2008). Party Competition between Unequals. Cambridge: Cambridge University Press.

Miller, A. H., Miller, W. E., Raine, A. S., \& Brown, T. A. (1976). A Majority Party in Disarray: Policy Polarization in the 1972 Election. The American Political Science Review, 70(3), 753-778. https://doi.org/10.2307/1959866

Nannestad, P., \& Paldam, M. (1997). The grievance asymmetry revisited: A micro study of economic voting in Denmark,1986-1992. European Journal of Political Economy, 13(1), 81-99. https://doi.org/10.1016/S0176-2680(96)00034-1

Nie, N. H., Verba, S., \& Petrocik, J. R. (1976). The changing American voter. Cambridge: Harvard University Press.

Nooy, W. D., \& Kleinnijenhuis, J. (2013). Polarization in the Media During an Election Campaign: A Dynamic Network Model Predicting Support and Attack Among Political Actors. Political Communication, 30(1), 117-138. https://doi.org/10.1080/10584609.2012.737417

Ospina, R., \& Ferrari, S. L. P. (2012). A general class of zero-or-one inflated beta regression models. Computational Statistics \& Data Analysis, 56(6), 1609-1623. https://doi.org/10.1016/j.csda.2011.10.005

Page, B. I., \& Brody, R. A. (1972). Policy Voting and the Electoral Process: The Vietnam War Issue. The American Political Science Review, 66(3), 979-995. https://doi.org/10.2307/1957489

Parmelee, J. H. (2013). Political journalists and Twitter: Influences on norms and practices. Journal of Media Practice, 14(4), 291-305. https://doi.org/10.1386/jmpr.14.4.291_1 
Parmelee, J. H., \& Bichard, S. L. (2011). Politics and the Twitter revolution: How tweets influence the relationship between political leaders and the public. Lanham: Lexington Books.

Pasek, J. (2016). When will Nonprobability Surveys Mirror Probability Surveys? Considering Types of Inference and Weighting Strategies as Criteria for Correspondence. International Journal of Public Opinion Research, 28(2), 269-291. https://doi.org/10.1093/ijpor/edv016

Petrocik, J. R. (1996). Issue Ownership in Presidential Elections, with a 1980 Case Study. American Journal of Political Science, 40(3), 825-850.

Pomper, G. M. (1972). From Confusion to Clarity: Issues and American Voters, 1956-1968. The American Political Science Review, 66(2), 415-428. https://doi.org/10.2307/1957786

Riker, W. H. (1986). The art of political manipulation. Yale Univ Pr.

Shaw, D. R. (2006). The Race to 270. The Electoral College and the Campaign Strategies of 200 and 2004. Chicago: The University of Chicago Press. Retrieved from http://www.press.uchicago.edu/ucp/books/book/chicago/R/bo4129894.html

Steenbergen, M. R., \& Scott, D. J. (2004). Contesting Europe? The salience of European integration as a party issue. In G. Marks \& M. R. Steenbergen (Eds.), European integration and political conflict (pp. 165-92). Cambridge: Cambridge University Press.

Vaccari, C., Valeriani, A., Barberá, P., Bonneau, R., Jost, J. T., Nagler, J., \& Tucker, J. (2013). Social media and political communication: A survey of Twitter users during the 2013 Italian general election. Rivista Italiana Di Scienza Politica, (3/2013). https://doi.org/10.1426/75245 
Van der Eijk, C., \& Franklin, M. N. (1996). Choosing Europe?: the European electorate and national politics in the face of union. Univ of Michigan Pr.

Verweij, P. (2012). Twitter Links Between Politicians and Journalists. Journalism Practice, 6(5-6), 680-691. https://doi.org/10.1080/17512786.2012.667272

Wagner, M. (2012). When do parties emphasise extreme positions? How strategic incentives for policy differentiation influence issue importance. European Journal of Political Research, 51(1), 64-88. https://doi.org/10.1111/j.1475-6765.2011.01989.x

Walgrave, S., Lefevere, J., \& Tresch, A. (2012). The Associative Dimension of Issue Ownership. Public Opinion Quarterly, 76(4), 771-782.

https://doi.org/10.1093/poq/nfs023 
Table 1. Risks and opportunities for party competition related to several policy issues, according to the issue yield model (PD, M5S, FI and LN in 2014; source: original data collection).

\begin{tabular}{|c|c|c|c|c|c|c|c|c|c|c|c|c|c|}
\hline \multirow{3}{*}{ Policy } & \multirow{3}{*}{$\begin{array}{l}\text { Agreement } \\
\text { at large }\end{array}$} & \multirow{2}{*}{\multicolumn{4}{|c|}{$\begin{array}{l}\text { Agreement } \\
\text { within the party }\end{array}$}} & \multicolumn{8}{|c|}{ Issue yield } \\
\hline & & & & & & \multicolumn{2}{|c|}{$\mathrm{PD}$} & \multicolumn{2}{|c|}{ M5S } & \multicolumn{2}{|c|}{ FI } & \multicolumn{2}{|c|}{$\mathrm{LN}$} \\
\hline & & $\mathrm{PD}$ & M5S & FI & $\mathrm{LN}$ & Pro & Anti & Pro & Anti & Pro & Anti & Pro & Anti \\
\hline Reduce spending for F-35 fighters & 88 & 92 & 94 & 70 & 83 & 0.88 & -0.48 & 0.93 & -0.13 & 0.68 & 0.24 & 0.82 & 0.14 \\
\hline Change towards a sustainable model of development & 87 & 93 & 94 & 81 & 79 & 0.89 & -0.49 & 0.93 & -0.13 & 0.79 & 0.13 & 0.79 & 0.18 \\
\hline Reduce income inequality & 84 & 91 & 91 & 76 & 74 & 0.85 & -0.45 & 0.89 & -0.09 & 0.74 & 0.19 & 0.73 & 0.23 \\
\hline Tougher attitude with India on the Enrica Lexie case & 80 & 81 & 78 & 90 & 98 & 0.69 & -0.29 & 0.73 & 0.07 & 0.90 & 0.03 & 0.98 & -0.02 \\
\hline More restrictive immigration laws & 78 & 57 & 79 & 90 & 95 & 0.32 & 0.08 & 0.75 & 0.06 & 0.89 & 0.04 & 0.95 & 0.02 \\
\hline Reduce taxes before fighting tax evasion & 75 & 56 & 78 & 88 & 78 & 0.29 & 0.11 & 0.74 & 0.06 & 0.87 & 0.05 & 0.77 & 0.20 \\
\hline Italian citizenship should be given to children born in Italy & 74 & 89 & 72 & 57 & 36 & 0.82 & -0.42 & 0.67 & 0.14 & 0.54 & 0.38 & 0.34 & 0.62 \\
\hline $\begin{array}{l}\text { Foreign companies selling services via the Internet should be taxed } \\
\text { here }\end{array}$ & 74 & 84 & 70 & 67 & 74 & 0.75 & -0.35 & 0.64 & 0.16 & 0.64 & 0.28 & 0.73 & 0.23 \\
\hline EU integration is a good thing & 71 & 91 & 70 & 60 & 41 & 0.85 & -0.45 & 0.64 & 0.16 & 0.57 & 0.35 & 0.39 & 0.57 \\
\hline Welfare chauvinism & 70 & 44 & 71 & 77 & 93 & 0.10 & 0.30 & 0.65 & 0.15 & 0.76 & 0.17 & 0.93 & 0.03 \\
\hline Heterologous insemination should be allowed & 68 & 77 & 77 & 72 & 59 & 0.63 & -0.23 & 0.73 & 0.07 & 0.70 & 0.22 & 0.57 & 0.39 \\
\hline Prostitution should be legalized & 64 & 67 & 79 & 76 & 83 & 0.46 & -0.06 & 0.75 & 0.06 & 0.74 & 0.19 & 0.82 & 0.14 \\
\hline A universal unemployment check should be introduced & 59 & 62 & 74 & 60 & 43 & 0.39 & 0.01 & 0.68 & 0.12 & 0.57 & 0.35 & 0.41 & 0.55 \\
\hline Introduce civil partnerships, even for gay couples & 58 & 73 & 66 & 45 & 38 & 0.57 & -0.17 & 0.59 & 0.21 & 0.41 & 0.51 & 0.36 & 0.61 \\
\hline Reduce the power of the judiciary & 49 & 27 & 40 & 72 & 81 & -0.18 & 0.58 & 0.28 & 0.52 & 0.70 & 0.22 & 0.80 & 0.16 \\
\hline Companies should have more freedom to hire and fire & 44 & 36 & 37 & 65 & 69 & -0.03 & 0.43 & 0.25 & 0.55 & 0.63 & 0.30 & 0.68 & 0.28 \\
\hline Founding NCD, Alfano betrayed Berlusconi & 40 & 22 & 40 & 77 & 66 & -0.24 & 0.64 & 0.28 & 0.52 & 0.76 & 0.17 & 0.64 & 0.32 \\
\hline To fight tax evasion, cash transaction limits should be lowered & 35 & 59 & 40 & 29 & 24 & 0.35 & 0.05 & 0.28 & 0.53 & 0.23 & 0.69 & 0.21 & 0.75 \\
\hline Soft drugs should be legalized & 31 & 43 & 53 & 23 & 24 & 0.09 & 0.31 & 0.44 & 0.37 & 0.18 & 0.75 & 0.21 & 0.75 \\
\hline Renzi's institutional reforms reduce democratic participation & 31 & 15 & 37 & 44 & 43 & -0.36 & 0.76 & 0.24 & 0.56 & 0.40 & 0.52 & 0.41 & 0.55 \\
\hline Italy should leave the Euro & 29 & 6 & 40 & 40 & 76 & -0.50 & 0.90 & 0.28 & 0.53 & 0.35 & 0.57 & 0.75 & 0.21 \\
\hline Italy should be split into macro-regions, with right to secession & 26 & 10 & 24 & 47 & 69 & -0.44 & 0.84 & 0.09 & 0.72 & 0.43 & 0.49 & 0.68 & 0.28 \\
\hline Abortion should me made more difficult & 25 & 19 & 21 & 35 & 36 & -0.29 & 0.69 & 0.06 & 0.75 & 0.30 & 0.63 & 0.34 & 0.62 \\
\hline
\end{tabular}


Table 2. Results of the classification of tweets, by two independent coders.

\begin{tabular}{cccccc} 
Agreement & $\begin{array}{c}\text { Expected } \\
\text { agreement }\end{array}$ & Kappa & $\begin{array}{c}\text { Standard } \\
\text { error }\end{array}$ & Z & P-value \\
\hline $81.75 \%$ & $7.99 \%$ & 0.80 & 0.01 & 73.79 & 0.0000 \\
\hline
\end{tabular}


Table 3. Counts of tweeted messages: positional, valence and non-issue messages.

\begin{tabular}{|c|c|c|c|c|c|c|c|c|}
\hline \multirow[b]{2}{*}{ Party } & \multicolumn{2}{|c|}{$\begin{array}{l}\text { Positional } \\
\text { issues }\end{array}$} & \multicolumn{2}{|c|}{$\begin{array}{l}\text { Valence } \\
\text { Issues }\end{array}$} & \multicolumn{2}{|c|}{$\begin{array}{l}\text { Non-issue } \\
\text { content }\end{array}$} & \multicolumn{2}{|c|}{ Total } \\
\hline & $\mathrm{N}$ & $\%$ & $\mathrm{~N}$ & $\%$ & $\mathrm{~N}$ & $\%$ & $\mathrm{~N}$ & $\%$ \\
\hline $\mathrm{Pd}$ & 19 & 16.8 & 24 & 21.2 & 70 & 61.9 & 113 & 100 \\
\hline M5S & 32 & 7.8 & 35 & 8.6 & 341 & 83.6 & 408 & 100 \\
\hline $\mathrm{Fi}$ & 192 & 14.7 & 202 & 15.5 & 913 & 69.9 & 1307 & 100 \\
\hline Ln & 160 & 33.1 & 27 & 5.6 & 296 & 61.3 & 483 & 100 \\
\hline $\mathrm{Se}$ & 79 & 48.5 & 21 & 12.9 & 63 & 38.7 & 163 & 100 \\
\hline FdI & 25 & 28.1 & 4 & 4.5 & 60 & 67.4 & 89 & 100 \\
\hline $\mathrm{Ncd}$ & 59 & 29.2 & 44 & 21.8 & 99 & 49.0 & 202 & 100 \\
\hline Tsipras & 8 & 11.9 & 11 & 16.4 & 48 & 71.6 & 67 & 100 \\
\hline Total & 574 & 20.3 & 368 & 13.0 & 1890 & 66.7 & 2832 & 100 \\
\hline
\end{tabular}


Table 4. Frequency distribution of tweets across positional issues, by party.

\begin{tabular}{|c|c|c|c|c|c|c|c|c|c|}
\hline \multirow{2}{*}{ Policy } & \multicolumn{8}{|c|}{ Party } & \multirow[t]{2}{*}{$\mathrm{N}$} \\
\hline & $\mathrm{Pd}$ & M5s & $\mathrm{Fi}$ & Ln & Ncd & FdI & Tsipras & $\mathrm{Se}$ & \\
\hline Change towards a sustainable model of development & & 8 & & & & & & & 8 \\
\hline Reduce spending for F-35 & & 5 & & & & & 2 & & 7 \\
\hline Reduce income inequality & 8 & 2 & 6 & & 4 & 1 & & & 21 \\
\hline Tougher attitude against India on the Enrica Lexie case & 1 & & & 2 & & 2 & & & 5 \\
\hline Foreign companies selling services via internet should be taxed & & & & & & & & & 0 \\
\hline Italian citizenship should be given to children born in Italy & & & & & & & & & 0 \\
\hline EU integration is a good thing & 1 & & 31 & 2 & 1 & & 2 & 54 & 91 \\
\hline Heterologous fecondation should be allowed & & & & & & & & & 0 \\
\hline Prostitution should be legalized & & & & & & & & & 0 \\
\hline Immigration laws should be more restrictive & & & 22 & 63 & 12 & 8 & 1 & 1 & 107 \\
\hline Before fighting tax evasion, taxes should be reduced & 1 & & 12 & & & & & & 13 \\
\hline Civil partnerships & & & & & & & & & 0 \\
\hline A universal unemployment check should be introduced & & 4 & & & & & & & 4 \\
\hline Welfare chauvinism & & & & 4 & & 4 & & & 8 \\
\hline To fight tax evasion, cash limit should be lowered & & & & & & & & & 0 \\
\hline Soft drugs should be legalized & & & & 2 & & 3 & & 3 & 8 \\
\hline Reduce the power of the judiciary & 1 & & 5 & 2 & & & & & 8 \\
\hline Companies should have more freedom to hire and fire & & 1 & 5 & & 5 & & 2 & 5 & 18 \\
\hline Founding NCD, Alfano betrayed Berlusconi & & & 28 & & 29 & & & & 57 \\
\hline Renzi's institutional reforms reduce democratic participation & 3 & 12 & 24 & 3 & 2 & 3 & & 2 & 49 \\
\hline Pro life & & & & & & 4 & & & 4 \\
\hline Italy should leave the Euro & & & 2 & 80 & & & 1 & 11 & 94 \\
\hline Italy should be split into macro-regions & & & & & & & & & 0 \\
\hline Other issues & 4 & & 57 & 2 & 6 & & & 3 & 72 \\
\hline Total & 19 & 32 & 192 & 160 & 59 & 25 & 8 & 79 & 574 \\
\hline
\end{tabular}


Table 5. Regression analysis of Twitter emphasis.

\begin{tabular}{lccc} 
& $\begin{array}{c}\text { Model } \\
(1)\end{array}$ & $\begin{array}{c}\text { Model } \\
(2)\end{array}$ & $\begin{array}{c}\text { Model } \\
(3)\end{array}$ \\
\hline Yield & $0.55^{* * *}$ & -0.34 & $-1.80^{* *}$ \\
& $(4.63)$ & $(-1.18)$ & $(-3.14)$ \\
Rel & - & -0.57 & $-0.65^{*}$ \\
& & $(-1.81)$ & $(-2.42)$ \\
Yield $\times$ Rel & - & $1.05^{*}$ & $1.26^{* *}$ \\
& & $(2.34)$ & $(2.69)$ \\
Diff & - & - & $-2.33^{*}$ \\
& & & $(-2.59)$ \\
Yield $\times$ Diff & - & - & $2.90^{* *}$ \\
& & & $(2.88)$ \\
Constant & $-0.54^{* * *}$ & -0.04 & $1.06^{*}$ \\
& $(-5.31)$ & $(-0.27)$ & $(2.24)$ \\
\hline Observations & 184 & 184 & 184 \\
Pseudo-R ${ }^{2}$ & .09 & .14 & .19 \\
\hline \hline
\end{tabular}

Note: table entries represent coefficients for the Tobit regression of issue emphasis on the hypothesized predictors (estimation based on robust standard errors, with observations clustered by party). The dependent variable is censored at $0 . T$-statistics reported in parentheses. ${ }^{*} p<0.05,{ }^{* *} p<0.01,{ }^{* * *} p<0.001$. 

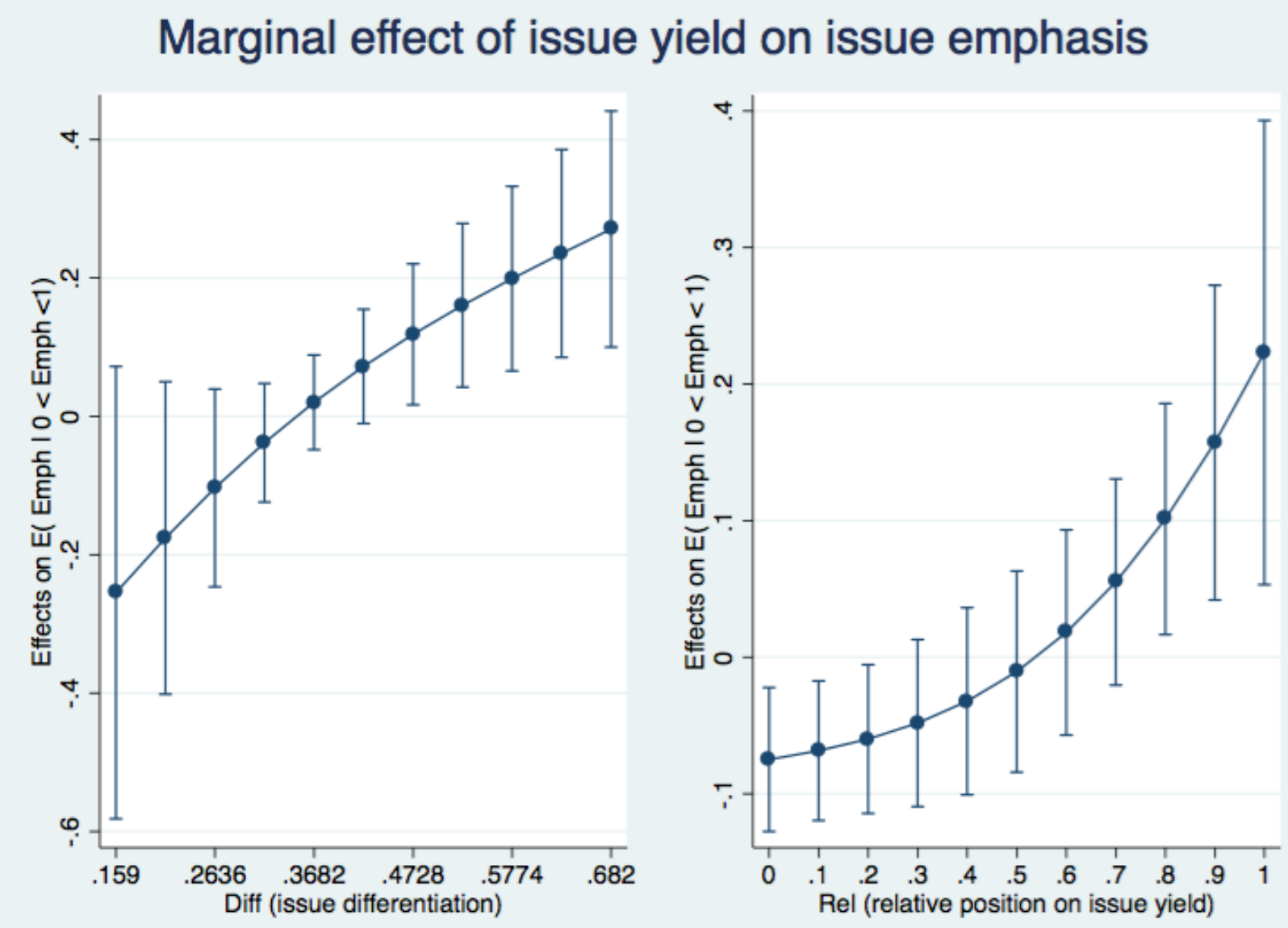

Note: the two charts represent graphically the Tobit model (3) reported Table 5. The left pane represents the conditional effect of issue yield on Twitter emphasis for varying values of issue differentiation. The right pane represents the same effects for varying values of the relative position of the parties with respect to the issues. Only the values for the subpopulation of issues with at least one tweet $E\left(E m p h_{i j} \mid E m p h_{i j}>0\right)$ are reported. Vertical bars represent $95 \%$ confidence intervals.

Figure 1. Multiparty dynamics: marginal effect of issue yield on issue emphasis 